\title{
Soldagem TIG com Oscilação Magnética Sincronizada
}

\author{
Thiago Resende Larquer ${ }^{1}$, Darlan Machado de Souza², Ruham Pablo Reis ${ }^{2}$ \\ ${ }^{1}$ Instituto Federal de Educação, Ciência e Tecnologia do Triângulo Mineiro - IFTM, Patos de Minas, MG, Brasil. \\ ${ }^{2}$ Universidade Federal de Uberlândia - UFU, Faculdade de Engenharia Mecânica, Uberlândia, MG, Brasil.
}

Recebido: 03 Maio, 2016

Aceito: 24 Ago., 2016

E-mails: thiagolarquer@gmail.com (TRL), darlanmachadodesouza@gmail.com (DMS),ruhamreis@ufu.br (RPR)
Este é um artigo publicado em acesso aberto (Open Access) sob a licença Creative Commons Attribution Non-Commercial, que permite uso, distribuição e reprodução em qualquer meio, sem restrições desde que sem fins comerciais e que 0 trabalho original seja corretamente citado.
Resumo: Na busca por melhorias de processos e técnicas de soldagem mecanizada/ automatizada, a combinação de modos operacionais, em adição à possibilidade de combinar níveis de corrente de soldagem, tem ganhado espaço. Por meio dessas combinações é possível variar a energia do arco, o que, aliado a movimentos impostos ao próprio arco, pode possibilitar distribuir a energia de forma otimizada para controlar a formação da solda. Uma forma de impor movimento ao arco é por oscilação magnética. Assim, este trabalho explora a sincronização da oscilação magnética com a soldagem TIG. Para tal, foi desenvolvido um sistema para controle simultâneo da oscilação magnética e da fonte de soldagem. Em seguida, foi feita uma caracterização da deflexão (em função da tensão do eletroímã, da corrente de soldagem e do comprimento do arco) baseada em filmagens de alta velocidade e proposto um modelo simples para a deflexão. A oscilação magnética com sincronização foi comparada à sem sincronização, tendo como base de análise o efeito sobre a largura dos cordões de solda. No caso da oscilação sincronizada, foi variado o nível de energia do arco de acordo com sua posição na peça, sendo possível aumentar a largura do cordão no lado da oscilação com maior energia do arco.

Palavras-chave: Oscilação magnética; Sincronização; TIG.

\section{GTA Welding with Synchronized Magnetic Oscillation}

\begin{abstract}
In the search for improvements in processes and mechanized/automated welding techniques, the combination of operational modes, in addition to the possibility of combining welding current levels, has gained attention. Through these combinations it is possible to vary the arc energy, which, along with movements applied to the arc itself, might allow distribute the energy in an optimized way to control the weld formation. One way to apply movement to the arc is by means of magnetic oscillation. Thus, this work exploits the synchronization between magnetic oscillation and the TIG welding process. For that, a system to control the magnetic oscillation and a welding power source simultaneously was devised. In the following, an arc deflection characterization was carried out (varying electromagnet voltage, welding current and arc length) based on high-speed filming and a simplified model for arc deflection proposed. The magnetic oscillation with synchronization was compared to the conventional one (with no synchronization), taking the effect on the weld bead width the basis for analyses. The synchronized oscillation technique successfully allowed vary the arc energy according to its position on the work piece, being possible to increase the weld width on the side of the oscillation with higher arc energy.
\end{abstract}

Key-words: Magnetic oscillation; Synchronization; TIG.

\section{Introdução}

A busca por melhorias de processos e técnicas de soldagem mecanizada/automatizada tem sido pauta no meio industrial já algum tempo, mas atualmente de forma ainda mais recorrente e intensa pela escassez de mão de obra qualificada [1,2]. Uma das formas de tentar explorar com mais eficiência (produtividade) os processos de soldagem de forma mecanizada/automatizada atualmente tem sido através da combinação de processos (abordagem híbrida) e mesmo de modos operacionais (polaridade e/ou modo de transferência metálica) dentro de um só processo, em adição à possibilidade de combinar níveis de corrente de soldagem. Especificamente no caso da combinação de modos operacionais (possível com fontes mais modernas) e de níveis de corrente, em uma mesma operação de soldagem é possível variar a energia do processo, tanto térmica (calor entregue à peça) quanto mecânica (pressão do arco e impacto das gotas, este último no caso de eletrodos consumíveis). Nesta linha, uma abordagem interessante, ainda não muito explorada, mas 
promissora, é utilizar este recurso para distribuir a energia de soldagem de forma otimizada na peça de trabalho para controlar a formação do cordão (material fundido e depositado). Isto poderia ser feito sincronizando os modos operacionais de soldagem e/ou os níveis de corrente utilizados com a posição do arco/tocha.

A posição do arco pode ser variada de forma mecânica (pela movimentação da tocha) ou magnética. A idéia de usar campos magnéticos para oscilar arcos de soldagem não é nova, foi idealizada e patenteada em 1960 [3]. Atualmente já existem sistemas comerciais para oscilar magneticamente arcos de soldagem e fontes de corrente alternada são usadas para controlar a oscilação. Recomendações gerais para construção de eletroímãs para deflexão de arcos de soldagem são dadas na literatura [4]. A oscilação magnética do arco é composta por uma série de deflexões magnéticas (movimento "pendular" do arco quando sujeito a um campo magnético variável e/ou alternado). O sentido de deflexão (esquerda e direita ou à frente e atrás em relação ao vetor velocidade de soldagem) depende da montagem/posicionamento do eletroímã em relação ao arco/tocha de soldagem, ou seja, do sentido das linhas de fluxo magnético produzidas pelo eletroímã; campo magnético paralelo/alinhado à direção de soldagem resulta em deflexão transversal/lateral do arco e campo magnético transversal à direção de soldagem resulta em deflexão longitudinal do arco. Já a inversão da posição (sentido de deflexão) do arco se dá pela inversão do sinal de controle (tensão/corrente) do eletroímã. $O$ alcance do movimento do arco em cada posição depende do nível de campo magnético aplicado e o tempo de permanência nesta posição depende do tempo de aplicação do campo magnético.

Talvez a principal vantagem em se utilizar osciladores magnéticos seja a facilidade para criar vários padrões de deflexão do arco, sejam eles para os lados e/ou para frente e para trás em relação à direção de soldagem. Em termos práticos, a deflexão magnética tem maior facilidade para defletir (oscilar) arcos em maiores frequências de movimentos e com maior precisão (sem problemas de inércia de mecanismos, folgas, etc., típicos de dispositivos mecânicos). Todavia, apesar da oscilação magnética poder ser utilizada em favor da soldagem, é preciso estar atento a eventuais problemas relacionados ao uso de campos magnéticos junto a arcos elétricos. Talvez a desestabilização do arco na presença de campos magnéticos intensos seja o principal problema. Estas instabilidades no arco podem até mesmo levar ao seu apagamento. Problemas com instabilidade e interrupção de arcos em soldagem MIG/MAG Duplo Arame e em soldagem TIG foram relatados na literarura [5-8]. A principal justificativa para tal fenômeno esta ligada aos campos magnéticos gerados pelos arcos que operam adjacentes um ao outro ou à aplicação de campos magnéticos relativamente elevados e à "rigidez" apresentada por estes arcos. Em termos práticos da deflexão magnética controlada de arcos, existem limitações em relação à distância (alcance) de deflexão, já que o arco fica preso em uma extremidade (eletrodo) e "balança" na outra (peça) como um pêndulo.

Vários estudos têm sido conduzidos para explorar a deflexão magnética no controle da geometria do cordão e, consequentemente, na mitigação de defeitos, bem como na melhoria de algumas propriedades mecânicas da junta soldada pelo refinamento do grão, etc. [9-14]. Entretanto, a oscilação magnética sincronizada com o processo de soldagem TIG não parace ter sido ainda explorada. Todavia, a literatura cita a utilização com sucesso de um sistema de sincronização da polaridade do eletrodo na soldagem MIG/MAG com a posição do arco para revestimentos soldados por oscilação mecânica da tocha [15].

Alguns modelos para prever a deflexão magnética do arco são encontrados na literatura. Alguns deles são relativamente antigos [16] e todos no geral são de solução relativamente complexa, por dependerem de outras características do arco, como distribuição de corrente e pressão [17]. Um modelo mais simples de deflexão magnética foi proposto, mas desenvolvido com foco na previsão de interações entre arcos adjacentes em MIG/MAG Duplo-Arame [18]. Apesar de ter sido usado neste caso para discutir a influência de um arco sobre o outro, nenhuma verificação experimental de tal modelo foi apresentada.

Assim, este trabalho explora o potencial da oscilação magnética do arco em uma nova abordagem. $O$ objetivo geral é sincronizar a oscilação magnética do arco com o processo de soldagem TIG (com níveis de corrente) e avaliar a potencialidade desta técnica para controlar/modificar os resultados da soldagem, mais especificamente em termos de geometria externa (largura) dos cordões produzidos. Com a sincronização proposta seria possível escolher a energia térmica e cinética do arco (nível de corrente de soldagem) para cada posição (combinação de arco à esquerda, à direita e no centro, utilizada neste trabalho, ou de arco à frente, atrás e no centro em relação ao vetor velocidade de soldagem), sendo a definição da posição (lateral/transversal, longitudinal ou central) e do tempo de aplicação destas energias em cada posição controlados pelo formato de onda (amplitudes e tempos) do sinal de tensão/corrente aplicado ao eletroímã. Uma descrição esquemática da ideia de sincronizar as posições do 
arco com seus níveis de energia através da utilização de oscilação magnética é mostrado na Figura 1 e na Figura 2. Foi realizada ainda uma caracterização da deflexão magnética versus parâmetros comuns à soldagem TIG (corrente de soldagem e comprimento de arco), além de proposto um modelo analítico simplificado para relacionar estes parâmetros e o campo magnético aplicado ao arco à deflexão resultante.

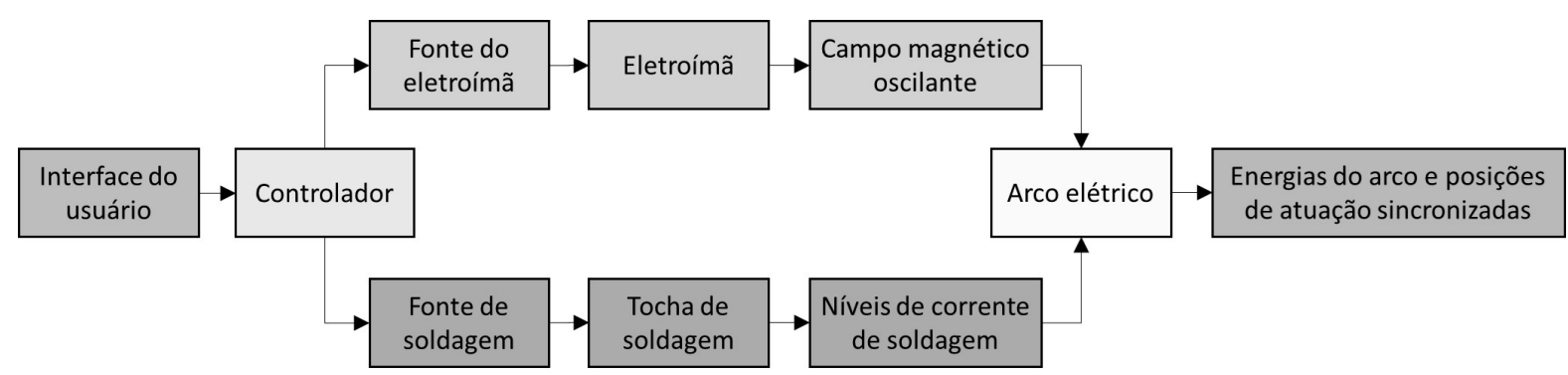

Figura 1. Representação esquemática da ideia de sincronizar as posições de arco com os seus níveis de energia usando oscilação magnética.

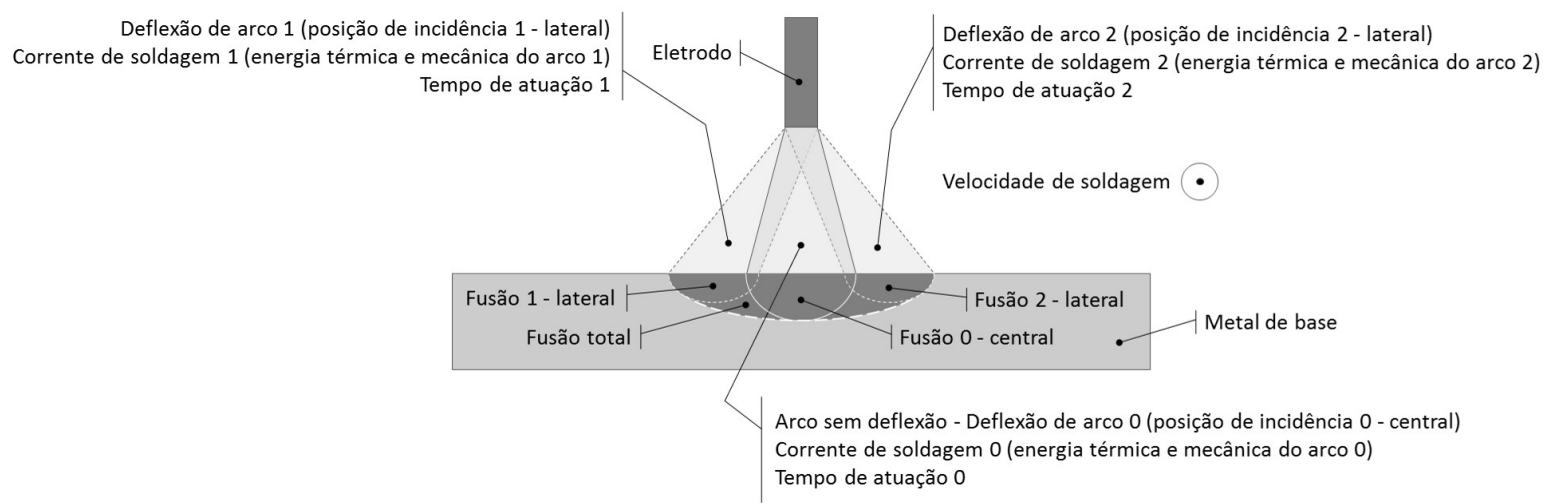

Figura 2. Vista esquemática em corte transversal da soldagem com o arco ao centro, à esquerda e à direita com diferentes níveis de energia em cada posição - oscilação magnética transversal sincronizada com os níveis de corrente.

Como exemplos de aplicações motivadoras para o desenvolvimento da sincronização de oscilação magnética com processos de soldagem a arco, já que a técnica aplicada aqui com soldagem TIG poderia também ser utilizada em soldagem MIG/MAG, tem-se a possibilidade de atuar de forma diferenciada na geometria dos cordões de solda (zona fundida e zona afetada pelo calor), no controle do tamanho de grão da solda (visando melhoria de propriedades resultantes), no controle da poça de fusão para soldagem fora de posição (evitando escorrimento do metal fundido), para soldagem de chanfros estreitos e passes de raiz, dentre outras.

\section{Metodologia Geral, Equipamentos e Materiais}

Primeiramente foi construído um eletroímã robusto de acordo com recomendações da literatura [4], a partir do aproveitamento de uma bobina de um contator eletromagnético e de um núcleo ferromagnético, utilizado para concentrar as linhas de fluxo magnético em uma região afastada do eletroímã. Também foi construído um suporte de alumínio para montagem do eletroímã em tochas de soldagem automáticas (de corpo reto) em geral. A construção deste conjunto (eletroímã e suporte) foi também baseada em equipamentos comerciais, nas necessidades relacionadas com a ideia proposta (sincronização da oscilação e processo) e em outros pontos da metodologia (utilização de filmagem em alta velocidade do arco para caracterização da deflexão, por exemplo). O eletroímã foi então caracterizado (utilizando um gaussímetro MAGNAFLUX PM-200) em termos de nível de tensão aplicada à bobina versus campo magnético produzido. 
Na sequência foi desenvolvido um sistema, incluindo hardware e software, para permitir controlar a oscilação magnética e a fonte de soldagem de forma sincronizada. O software foi desenvolvido utilizando a plataforma LabVIEW $^{\circledR}$. O hardware do sistema foi composto de um driver para acionamento do eletroímã a partir de um sinal DC (Direct Current), provindo de uma fonte DC (Minipa MPL-3305M), e de um sistema para condicionamento e aquisição de sinais (tensão aplicada ao eletroímã, corrente de soldagem e tensão de arco). Foi construído e utilizado um circuito inversor de tensão/corrente integrado ao sistema de oscilação/sincronização para que sinal elétrico aplicado ao eletroímã fosse alternado, permitindo, assim, a inversão do sentido de deflexão do arco. Em termos de controle, o software desenvolvido permite a seleção dos tempos de parada lateral (direita e/ou esquerda independentes) ou longitudinal (à frente e/ou atrás independentes) e de parada central do arco. A seleção da amplitude de deflexão do arco, nível de tensão aplicada ao eletroímã (igual para cada posição lateral de deflexão), foi feita diretamente na fonte de tensão DC utilizada. A fonte de soldagem multiprocesso utilizada (IMC DIGIPlus A7) permite, a partir de um sinal de comando externo (VIA I/O), mudar o modo operacional e/ou níveis de corrente durante a soldagem para valores pré-programados. Assim, foi possível escolher o nível de corrente em cada posição do arco (lateral esquerda, centro e lateral direita).

A seguir, foi feita uma caracterização da deflexão; geração de curvas de valor de deflexão em função da tensão do eletroímã, da corrente de soldagem e do comprimento do arco baseada em filmagens de alta velocidade e análise de imagens do arco. Neste caso, o arco e peça (bloco de cobre refrigerado) permaneceram estacionários. Esta caracterização experimental foi comparada a um modelo físico-matemático simplificado desenvolvido. Além disso, foi feita uma avaliação do sincronismo entre a oscilação magnética e os níveis de corrente de soldagem baseadas nos sinais elétricos adquiridos e nas imagens capturadas do arco. Para todas as filmagens foi utilizada uma câmera NAC Hi-Dcamll a uma frequência de 2000 quadros por segundo e com imagens coloridas de resolução de 640X128 pixels.

Por fim, foi avaliada a oscilação magnética sincronizada com níveis de corrente para soldagem TIG. Foram realizadas soldagens autógenas de $200 \mathrm{~mm}$ de comprimento com deflexão lateral/transversal (à direção de soldagem) sobre chapas de aço carbono 1020 ( $3 \mathrm{~mm}$ de espessura, $250 \mathrm{~mm}$ de comprimento e $60 \mathrm{~mm}$ de largura), variando o nível de corrente de soldagem de acordo com a posição do arco. Também foram realizados ensaios com oscilação magnética sem qualquer sincronia com o processo de soldagem e também sem oscilação (referências para comparação com os resultados obtidos com a oscilação magnética sincronizada). As chapas foram limpas (por lixadeira elétrica manual) e receberam uma marcação da linha de centro (por meio de um punção) para alinhamento da soldagem. Nesta avaliação as soldagens foram feitas com os corpos de prova sobre um suporte de aço com cobrejunta de cobre. Os resultados foram avaliados em termos de geometria e aparência superficial dos cordões formados. Especificidades da metodologia utilizada são apresentadas nos itens seguintes. A bancada experimental com os principais equipamentos utilizados é ilustrada na Figura 3. A Tabela 1 apresenta os parâmetros gerais do processo TIG utilizados.

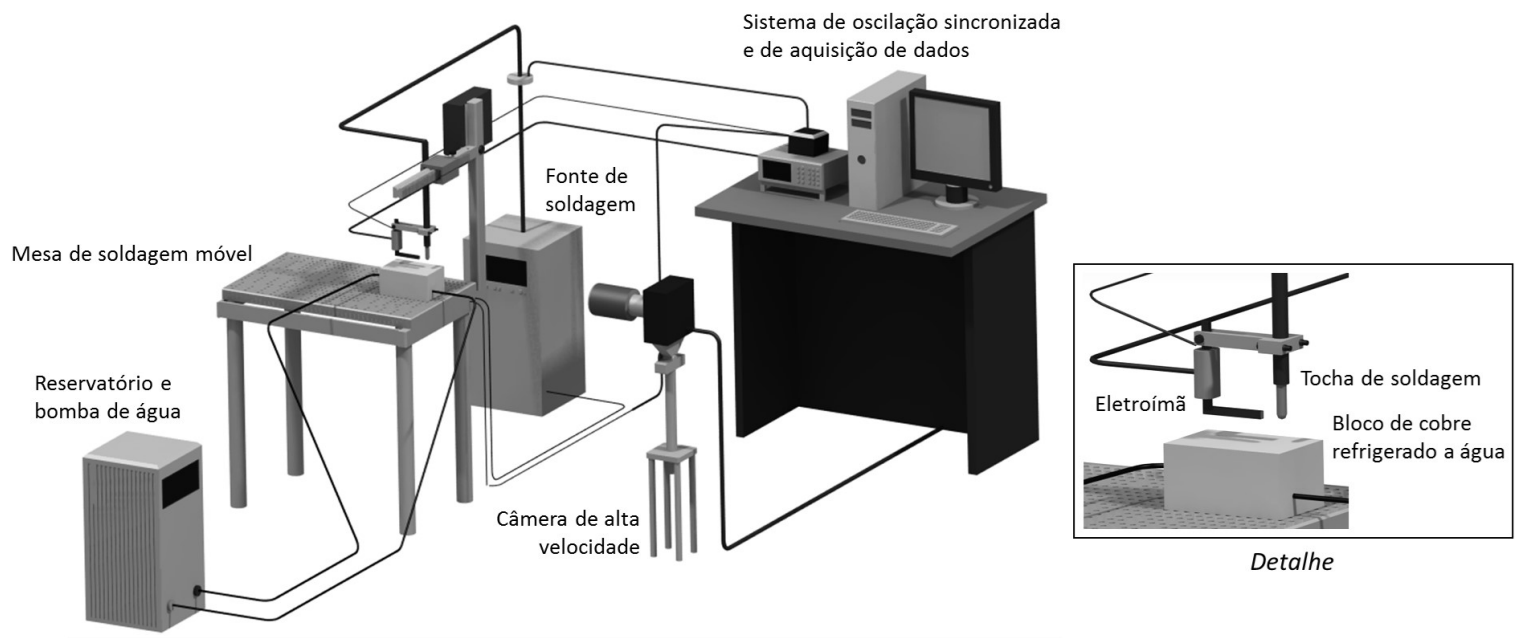

Figura 3. Esquema da bancada de ensaios (para a avaliação da soldagem propriamente dita, o bloco de cobre foi substituído por chapas de aço). 
Tabela 1. Parâmetros gerais do processo TIG utilizados.

\begin{tabular}{lc}
\hline \multicolumn{1}{c}{ Distância eletrodo-peça - comprimento de arco* $[\mathrm{mm}]$} & $\mathbf{3 , 5} / \mathbf{6 , 5} / \mathbf{1 0 , 0}$ \\
Distância eletroímã-arco/eletrodo $[\mathrm{mm}]$ & 15 \\
Distância eletroímã-peça $[\mathrm{mm}]$ & 3 \\
Velocidade de soldagem ** $[\mathrm{mm} / \mathrm{min}]$ & 200 \\
Gás de proteção & Argônio \\
Vazão de gás de proteção [l/min] & 14 \\
Composição do eletrodo & EWTh-2 \\
Diâmetro do eletrodo [mm] & 4 \\
Ângulo de ponta do eletrodo & $60^{\circ}$ \\
Ângulo de inclinação do eletrodo/tocha & $0^{\circ}$ \\
\hline
\end{tabular}

*O comprimento do arco foi variado em três níveis para a "Caracterização da deflexão do arco" (item 3) e fixado em 6,5 mm para a "Oscilação magnética sincronizada com o processo TIG" (item 4). **Para a "Caracterização da deflexão do arco" (item 3) a velocidade de soldagem foi nula (arco estacionário).

\section{Caracterização da Deflexão do Arco}

\subsection{Modelo teórico simplificado para deflexão magnética em soldagem TIG}

De forma a tentar prever o comportamento (extensão da deflexão) de arcos de soldagem, especificamente do processo TIG, submetidos a campos magnéticos externos, foi desenvolvido um modelo simplificado para a deflexão do arco. Este modelo foi baseado em trabalho já desenvolvido que, no caso, apresentou um modelo concebido para interação entre arcos adjacentes na soldagem MIG/MAG Duplo-Arame [18]. Toma-se a Figura 4 como base para a deflexão magnética do arco TIG.

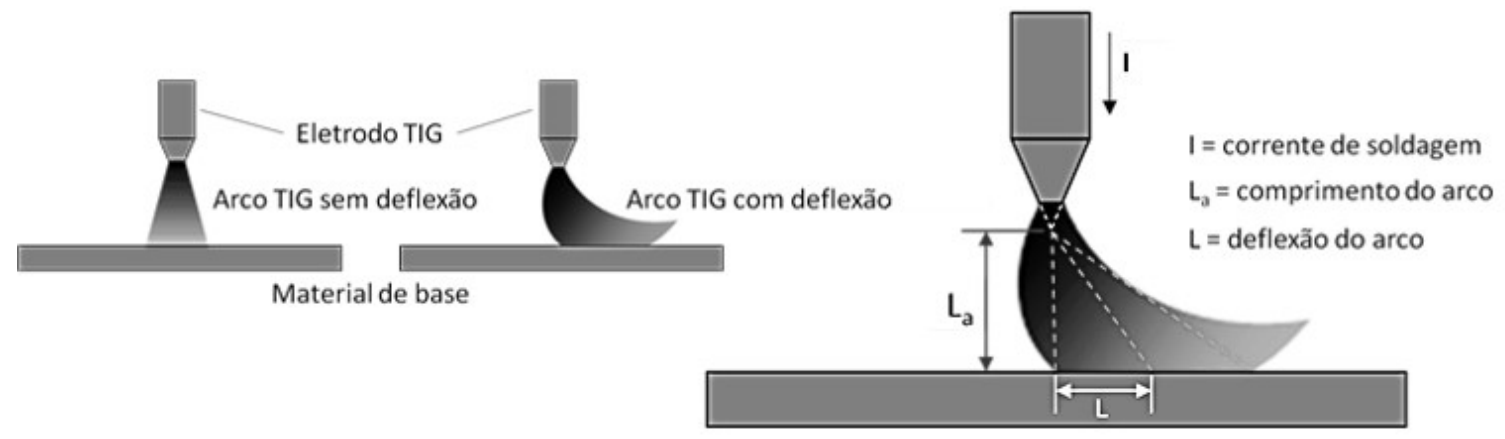

Figura 4. Esquema do arco TIG submetido a deflexão por campo magnético externo.

Sabe-se que o campo magnético externo (imposto pelo eletroímã) induz uma força no arco elétrico. Desprezando a força devido ao campo elétrico (provocada pela tensão do arco), a força eletromagnética ou força de Lorentz $\left(F_{M}\right)$ então atuante em um volume unitário do arco pode ser escrita como na Equação 1:

$$
F_{M}=j \times B
$$

Onde: $j=\frac{I}{S}=\frac{I}{\pi R^{2}}=$ densidade de corrente elétrica; sendo $S=$ secção transversal do arco elétrico e $I=$ corrente elétrica que passa pelo arco.

Assim, rescrevendo-se a Equação 1, obtém-se a Equação 2:

$$
F_{M}=\frac{I}{\pi R^{2}} B \mid s
$$

Sabe-se também que: Força = massa $\times$ aceleração. 
Desta forma, para uma unidade de volume do arco, a Equação 2 é rescrita como na Equação 3:

$$
F_{M}=\rho \frac{d^{2} L}{d t^{2}}
$$

Onde: $L=$ deflexão do arco; $\rho=$ densidade do fluido (arco).

Reorganizando os termos da Equação 3, tem-se a Equação 4:

$$
\frac{F_{M}}{\rho}=\frac{d^{2} L}{d t^{2}}
$$

Ao integrar no domínio do tempo ambos os lados da Equação 4, tem-se a Equação 5:

$$
\frac{F_{M}}{\rho} t+C_{1}=\frac{d L}{d t}
$$

Onde: $C_{1}=$ constante de integração.

Integrando agora a Equação 5, obtém-se a Equação 6:

$$
\frac{F_{M} t^{2}}{2 \rho}+C_{1} t+C_{2}=L
$$

Onde: $C_{2}=$ constante de integração.

Para se encontrar as constantes de integração da Equação 6, são utilizadas as seguintes condições de contorno:

$$
\begin{aligned}
& \text { Parat }=0: \frac{d L}{d t}=0 \quad e C_{1}=0 \\
& \text { Parat }=0: L=0 \quad e C_{2}=0
\end{aligned}
$$

Isolando o termo da deflexão (L), tem-se a formulação dada pela Equação 7:

$$
L=\frac{F_{M} t^{2}}{2 \rho}
$$

Utiliza-se da definição de velocidade média para encontrar o parâmetro do tempo (t):

$$
\text { Velocidade }=\frac{\Delta \text { deslocamento }}{\Delta \text { tempo }}
$$

Desta forma, chega-se à Equação 8:

$$
u=\frac{L_{a}}{t} ; t=\frac{L_{a}}{u}
$$

Onde: $u$ = velocidade do jato de plasma (arco); $L_{a}=$ distância entre eletrodo e peça (comprimento do arco).

Substituindo as Equações 2 e 8 na Equação 7, tem-se a Equação 9:

$$
L=\frac{B L_{a}^{2} I}{2 \pi R^{2} \mathrm{u}^{2} \rho}
$$

Assumindo que a pressão $(P)$ do arco, definida abaixo, é totalmente transformada em um fluxo dinâmico de fluido até encontrar a peça, pode-se usar a equação de Bernoulli para se obter a velocidade do jato de plasma [18], resultando na Equação 10: 


$$
P=\frac{I^{2} \mu_{0}}{4 \pi^{2} R^{2}}=\frac{I \mu_{0}}{4 \pi} j
$$

Onde: $\mu_{0}=$ permeabilidade magnética do vácuo.

Como na literatura [18], assumindo que a pressão do arco é totalmente transformada em fluxo de fluido próxima à chapa, pode-se então simplificar a equação de Bernoulli, resultando na Equação 11:

$$
P=\frac{\rho u^{2}}{2}
$$

Relacionando as Equações 10 e 11 e isolando o termo da velocidade $u$, tem-se a Equação 12:

$$
u^{2}=\frac{I^{2} \mu_{0}}{2 \pi^{2} R^{2} \rho}
$$

Enfim, substituindo a Equação 12 na Equação 9, encontra-se a formulação do cálculo da deflexão de um arco TIG, que é dada pela Equação 13:

$$
L=\frac{I B}{\pi R^{2} \rho} \times \frac{L_{a}^{2}}{2 \frac{I^{2} \mu_{0}}{2 \pi^{2} R^{2} \rho}}
$$

Simplificando a Equação 13, chega-se à Equação 14:

$$
L=B \frac{L_{a}^{2} \times \pi}{I \times \mu_{0}}
$$

Verificando a coerência da Equação 14 por análise dimensional:

$$
\begin{aligned}
& L:[m] \\
& B:[\text { Gauss }]=10^{-4}[\text { Tesla }] \\
& L_{a}:[m] \\
& \mu_{0}: 1,2566 \times 10^{-6}\left[\text { Tesla } \times \frac{m}{A}\right] \\
& I:[A]
\end{aligned}
$$

Assim, tem-se a Equação 15:

$$
L=[\text { Tesla }] \frac{\left[m^{2}\right]}{[A] \times\left[\text { Tesla } \times \frac{m}{A}\right]}=[\mathrm{m}]
$$

Como mostrado na Equação 15, a formulação deduzida para a deflexão é dimensionalmente coerente. A representatividade deste modelo será avaliada na sequência, depois de apresentados os resultados experimentais da medição da deflexão magnética de arcos TIG.

\subsection{Deflexão magnética experimental em soldagem TIG}

Primeiramente foi feita uma verificação da relação entre a tensão aplicada ao eletroímã (tomada como variável controlada pela grandeza apresentada e facilidade de controle) e a densidade de fluxo de campo magnético produzida. A linha de extensão abaixo do eletrodo de tungstênio foi tomada como referência (ponto de medição) e 
as medições de campo magnético feitas sem o arco, com a sonda posicionada na metade da distância eletrodo-peça. Como mostrado na Figura 5, a relação entre tensão do eletroímã e densidade de campo magnético produzida é linear.

Então foram feitos ensaios variando a corrente de soldagem e o comprimento de arco para diferentes níveis de campo magnético e com filmagem de alta velocidade para possibilitar a medição da deflexão de arco resultante. A Figura 6 ilustra o método de medição da deflexão do arco com base nas imagens capturadas, onde as referências $C$ e $D$ representam os pontos onde o arco visualmente perde o contato com a chapa. As medições foram executadas com auxílio do software ImageJ. O diâmetro do eletrodo de tungstênio utilizado, 4,09 mm (média de três medidas feita com micrômetro externo Starrett 436.2), foi utilizado como fator de escala para calibração das imagens.

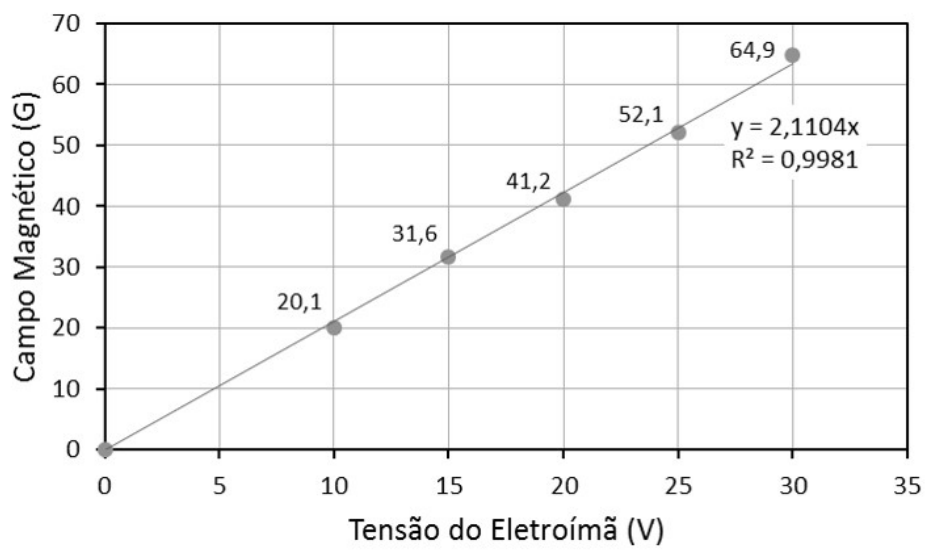

Figura 5. Relação entre a tensão aplicada ao eletroímã e densidade de campo magnético produzida para uma distância entre a face frontal do núcleo do eletroímã e o arco elétrico (linha de extensão abaixo do eletrodo) de $15 \mathrm{~mm}$; Corrente aplicada ao eletroímã (mA) = 12,8 * Tensão do Eletroímã (V).

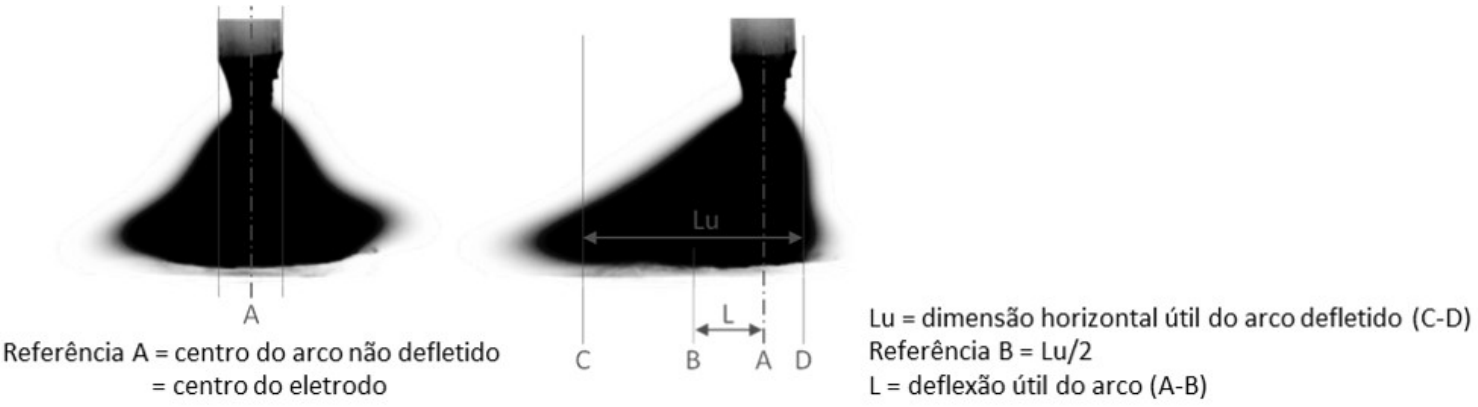

Figura 6. Ilustração do método de medição da deflexão do arco (a cor das imagens foi invertida para facilitar a visualização do arco).

A Tabela 2 e a Tabela 3 mostram, respectivamente, os testes com resultados da avaliação experimental do efeito da corrente de soldagem e do comprimento do arco na deflexão do arco pelo campo magnético. Como indicado, alguns testes tiverem instabilidades do arco e não permitiram medições adequadas. Nestes casos, o arco estava tão defletido que começava a se "descolar/desconectar" (inclusive com variação de extensão da deflexão) da chapa de forma muito similar a trabalhos anteriores [6-8]. Essas instabilidades reafirmam que arcos com menores correntes de soldagem e/ou comprimentos maiores são menos rígidos mecanicamente (mais fáceis de defletir) e são, ao mesmo tempo, menos rígidos termicamente (mais fáceis de apagar). Isso parece explicar por que em trabalho anterior não foram realizados experimentos/medições de deflexão de arco em situações conjuntamente com campos magnéticos elevados, correntes de soldagem baixas e comprimentos de arco elevados [17]. Os valores 
Tabela 2. Ensaios e resultados da avaliação experimental do efeito da corrente de soldagem na deflexão.

\begin{tabular}{ccccccc}
\hline Ensaio & La [mm] & I [A] & B [Gauss] & L direito [mm] & L esquerdo [mm] & L médio [mm] \\
$1^{*}$ & 6,5 & 100 & 20,1 & - & - & - \\
$2^{*}$ & 6,5 & 100 & 31,6 & - & - & - \\
$3^{*}$ & 6,5 & 100 & 41,2 & - & - & - \\
$4^{*}$ & 6,5 & 100 & 52,1 & - & - & - \\
$5^{*}$ & 6,5 & 100 & 64,9 & - & 2,82 & 2,89 \\
6 & 6,5 & 200 & 20,1 & 2,97 & 4,89 & 5,29 \\
7 & 6,5 & 200 & 31,6 & 5,68 & 6,26 & 6,53 \\
8 & 6,5 & 200 & 41,2 & 6,80 & 9,12 & 8,99 \\
9 & 6,5 & 200 & 52,1 & 8,86 & 10,90 & 10,93 \\
10 & 6,5 & 200 & 64,9 & 10,96 & 2,96 & 3,09 \\
11 & 6,5 & 300 & 20,1 & 3,19 & 4,95 & 4,93 \\
12 & 6,5 & 300 & 31,6 & 4,92 & 6,53 & 6,73 \\
13 & 6,5 & 300 & 41,2 & 6,93 & 8,69 & 8,34 \\
14 & 6,5 & 300 & 52,1 & 7,99 & 9,48 & 9,45 \\
\hline
\end{tabular}

La = comprimento do arco; I = corrente de soldagem; B = densidade de campo magnético; L = deflexão do arco; Distância eletroímã-arco/ eletrodo = $15 \mathrm{~mm}$. *Nestes testes não foi possível medir de maneira adequada a deflexão do arco por incidência de instabilidades.

Tabela 3. Ensaios e resultados da avaliação experimental do efeito do comprimento de arco na deflexão.

\begin{tabular}{ccccccc}
\hline Ensaio & La [mm] & I [A] & B [Gauss] & L direito [mm] & L esquerdo [mm] & L médio [mm] \\
1 & 6,5 & 200 & 20,1 & 2,97 & 2,82 & 2,89 \\
2 & 6,5 & 200 & 31,6 & 5,68 & 4,89 & 5,29 \\
3 & 6,5 & 200 & 41,2 & 6,80 & 6,26 & 6,53 \\
4 & 6,5 & 200 & 52,1 & 8,86 & 9,12 & 8,99 \\
5 & 6,5 & 200 & 64,9 & 10,96 & 10,90 & 10,93 \\
6 & 10 & 200 & 31,6 & 12,44 & 9,14 & 10,79 \\
7 & 10 & 200 & 41,2 & 13,75 & 10,68 & 12,22 \\
$8^{*}$ & 10 & 200 & 52,1 & 11,40 & 10,37 & 10,89 \\
9 & 3,5 & 200 & 31,6 & 2,61 & 0,96 & 1,79 \\
10 & 3,5 & 200 & 41,2 & 3,69 & 1,58 & 2,63 \\
11 & 3,5 & 200 & 52,1 & 4,22 & 2,80 & 3,51 \\
\hline
\end{tabular}

La = comprimento do arco; I = corrente de soldagem; B = densidade de campo magnético; L = deflexão do arco; Distância eletroímã-arco/ eletrodo = $15 \mathrm{~mm}$. Obs: Os testes de 1 a 5 correspondem aos testes de 6 a 10 da Tabela 2. *Neste teste não foi possível medir de maneira adequada a deflexão do arco por incidência de instabilidades.

extremos de campo magnético (20 e 60 Gauss) não foram utilizados para os comprimentos de arco de 10 e 3,5 mm porque para 20 Gauss a deflexão do arco seria muito pequena (principalmente para o arco de 3,5 mm) e já para 60 Gauss seria alto o risco de instabilidade/apagamento do arco (principalmente para o arco de $10 \mathrm{~mm}$ ). Assim, para o caso do efeito do comprimento do arco, foi feita uma varredura nos níveis intermediários de campo magnético.

Como indicado na Figura 7, quanto maior o campo magnético, maior a deflexão do arco. Considerando também que arcos sem campo magnético externo apresentam deflexão zero (as curvas Deflexão do Arco versus Campo Magnético passam pelo zero), este comportamento se mostrou bastante linear, como indicado pela Equação 14 teórica desenvolvida. Pela Figura 7 (à esquerda), também de acordo com a Equação 14, os experimentos indicam que arcos com maiores correntes apresentam deflexões ligeiramente menores, já que são mais rígidos mecanicamente (ação do jato de plasma). Entretanto, uma análise mais consistente não pôde ser feita pela impossibilidade de medir a deflexão de arcos com $100 \mathrm{~A}$ pela presença de instabilidades. Como também indicado na Figura 7 (à direita), para uma mesma corrente de soldagem (200 A), as deflexões aumentaram com o comprimento do arco, comportamento previsto pela Equação 14 e também por modelos precedentes [16]. A Figura 8 mostra 

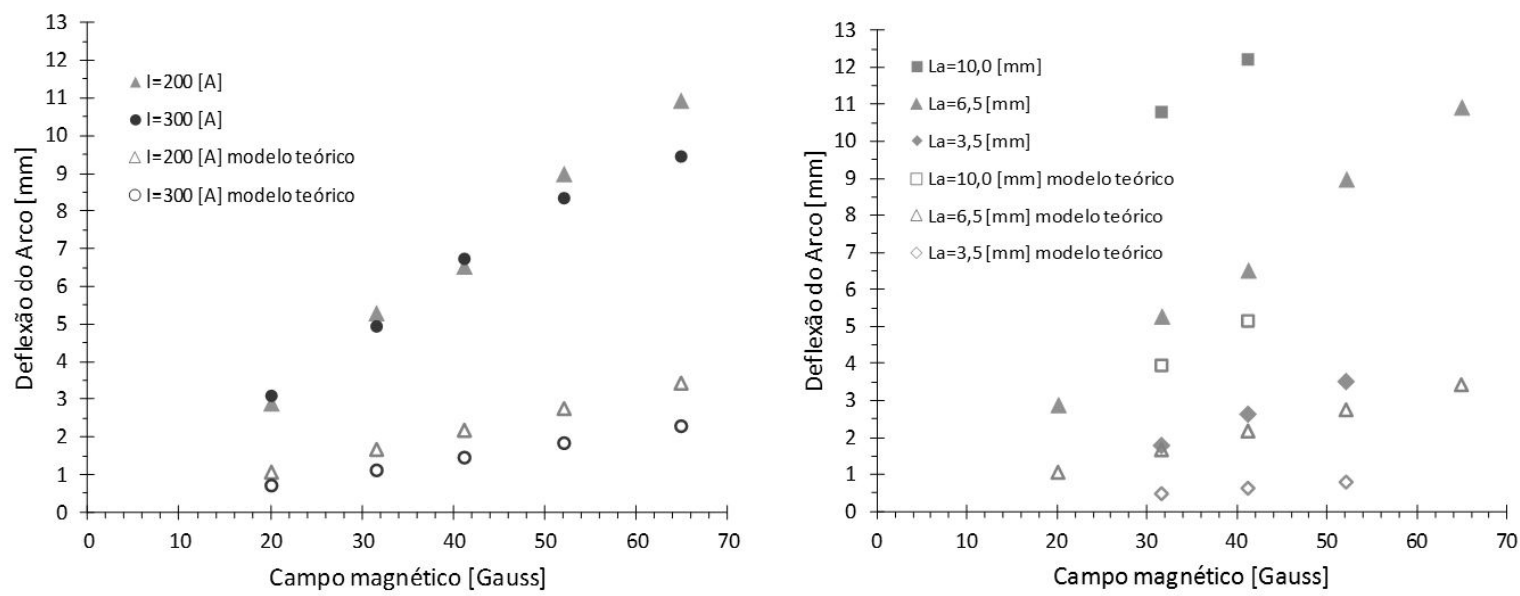

Figura 7. (à esquerda) Resultados experimentais versus resultados teóricos para efeito do campo magnético e da corrente de soldagem na deflexão do arco; (à direita) Resultados experimentais versus resultados teóricos para efeito do campo magnético e do comprimento de arco na deflexão do arco.

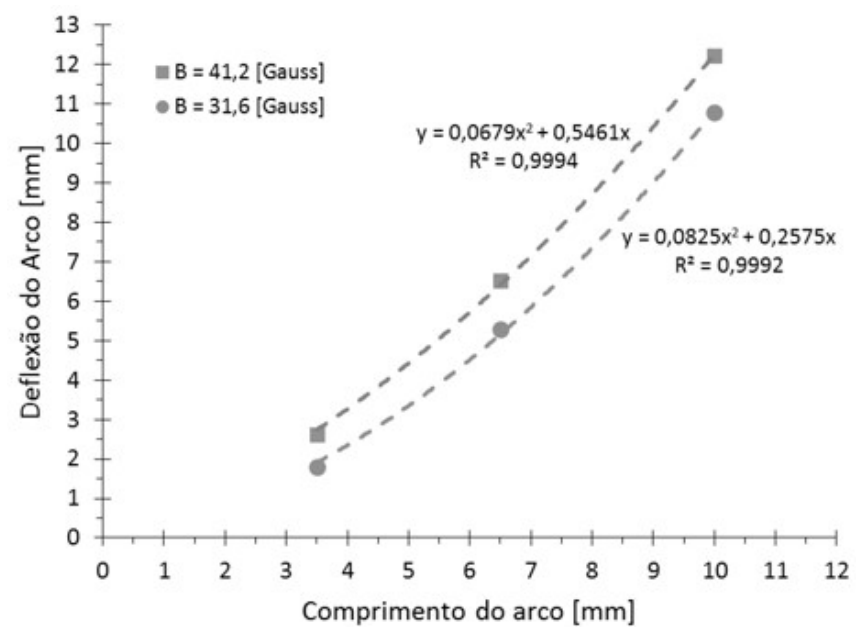

Figura 8. Detalhe do efeito do comprimento de arco na deflexão do mesmo.

em detalhe a influência do aumento do comprimento do arco sobre a deflexão para dois níveis intermediários de campo magnético. Considerando que arcos "sem comprimento" apresentam deflexão zero, a deflexão variou com o quadrado do comprimento do arco, como fora previsto pela Equação 14 e também por modelos anteriores [16].

\subsection{Deflexão magnética experimental versus teórica}

Como é possível notar na Figura 7 e na Figura 8, o modelo teórico da deflexão magnética do arco, Equação 14, indica o mesmo comportamento verificado nos experimentos; a deflexão é diretamente proporcional ao campo magnético e ao comprimento do arco ao quadrado e inversamente proporcional à corrente de soldagem. Entretanto, apesar de representar a tendência de comportamento real do fenômeno de deflexão do arco, o modelo teórico de deflexão não conseguiu estimar de maneira razoável a extensão da deflexão real. Possíveis motivos para tal discrepância nos resultados podem estar relacionados às simplificações feitas, tais como: desconsiderar a distribuição de corrente e pressão no arco (como considerado na literatura [17]), dificuldade em medir o campo magnético que efetivamente age no arco (certamente o campo real não é uniforme e é diferente do campo magnético medido no ar, até pela interação com o campo magnético do próprio arco), desconsiderar a mudança do comprimento do $\operatorname{arco}\left(\mathrm{L}_{a}\right)$ com a deflexão do mesmo e também o valor utilizado para a permeabilidade magnética no arco (pode ser bem diferente da permeabilidade magnética no vácuo). 


\subsection{Avaliação "visual" do sincronismo entre oscilação magnética e corrente de soldagem}

O sincronismo entre a capacidade de fusão do arco (representado pela corrente de soldagem) e a posiçãotempo de aplicação desta capacidade de fusão foi demonstrado por meio de imagens e sinais elétricos. A Tabela 4 lista os parâmetros utilizados para esta finalidade. Para uma tensão do eletroímã (deflexão) fixada em $20 \mathrm{~V}$, foram utilizados três posições-tempos de parada e três níveis de corrente diferentes. O resultado do comportamento do arco elétrico (posição e "volume") em cada fase - combinação de corrente de soldagem e posição-tempo de atuação - é apresentado na Figura 9.

Tabela 4. Parâmetros para demonstração do sincronismo entre oscilação magnética (posição-tempo do arco) e corrente de soldagem (comprimento de arco =6,5 $\mathrm{mm}$ ).

\begin{tabular}{cccccccc}
\hline Ensaio & $\begin{array}{c}\text { Tensão do } \\
\text { Eletroímã } \\
{[\text { [V] }}\end{array}$ & $\begin{array}{c}\text { Tempo de } \\
\text { Parada } \\
\text { Esquerda } \\
{[\mathrm{ms}]}\end{array}$ & $\begin{array}{c}\text { Tempo de } \\
\text { Parada } \\
\text { Central }[\mathrm{ms}]\end{array}$ & $\begin{array}{c}\text { Tempo de } \\
\text { Parada } \\
\text { Direita [ms] }\end{array}$ & $\begin{array}{c}\text { Corrente de } \\
\text { Soldagem } \\
\text { Esquerda }[\mathrm{A}]\end{array}$ & $\begin{array}{c}\text { Corrente de } \\
\text { Soldagem } \\
\text { Central } \\
{[\text { A }]}\end{array}$ & $\begin{array}{c}\text { Corrente de } \\
\text { Soldagem } \\
\text { Direita } \\
{[\text { A] }}\end{array}$ \\
\hline 1 & 20 & 250 & 500 & 750 & 100 & 200 & 300 \\
\hline
\end{tabular}

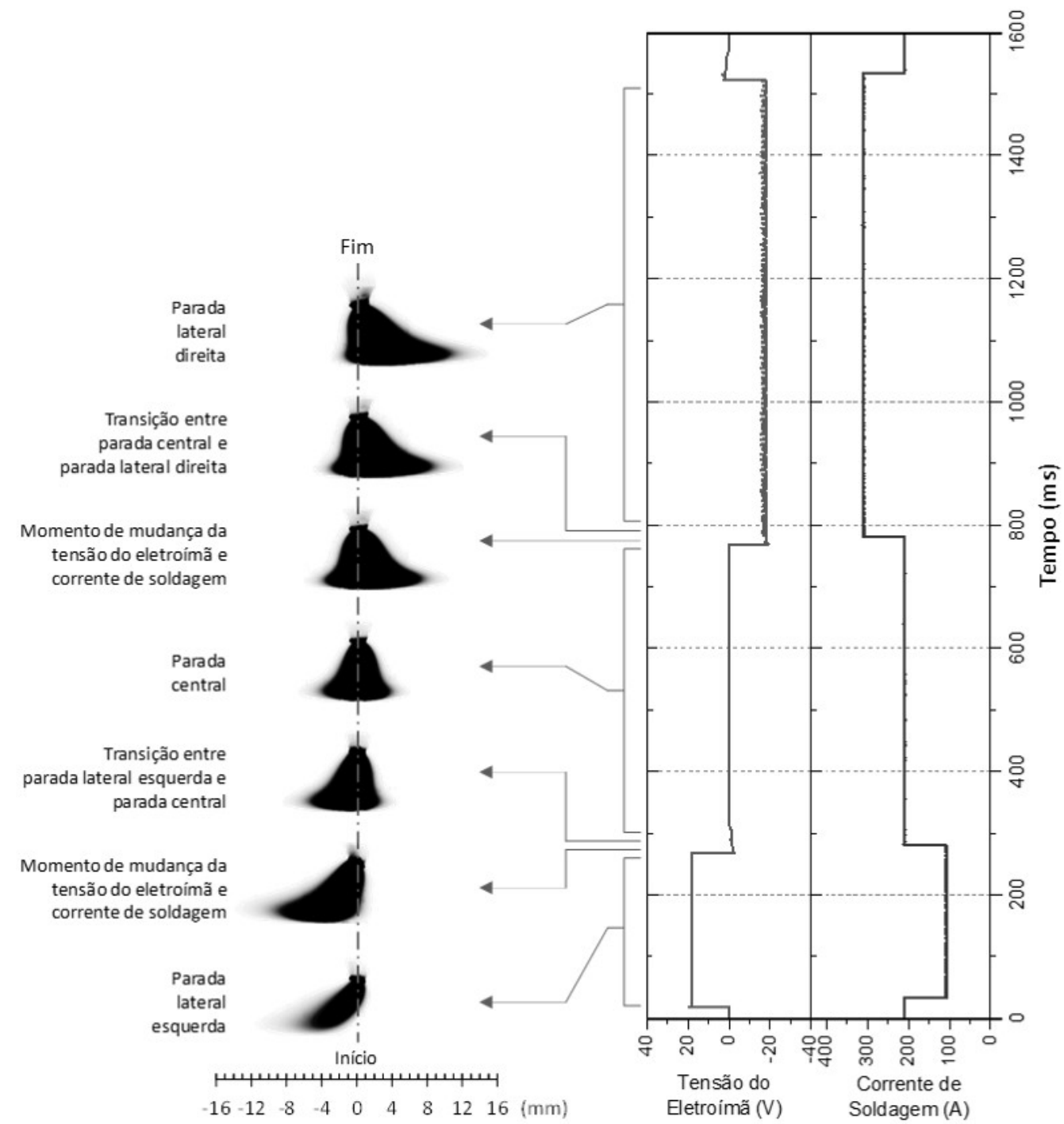

Figura 9. Sequência de imagens do arco para diferentes fases de tensão do eletroímã (campo magnético - nível de deflexão) e de corrente de soldagem, demonstrando o sincronismo entre posição do arco (oscilação magnética) e corrente de soldagem (a cor das imagens foi invertida para facilitar a visualização do arco). 
Nota-se, pela Figura 9, que de início o arco, quando defletido para a esquerda (parada lateral esquerda), apresenta menor "volume" devido ao menor nível de corrente de soldagem utilizado (menor grau de ionização). Na sequência, passado o pequeno tempo de aplicação deste nível baixo de corrente, quando a tensão do eletroímã vai à zero, a corrente de soldagem muda para um nível intermediário, o que fica evidente pelo aumento de "volume" do arco. Rapidamente o arco chega então à posição sem deflexão (parada central) mantendo este nível de corrente de soldagem intermediário. A seguir, passado o tempo de aplicação deste nível intermediário de corrente, a tensão do eletroímã vai para o mesmo nível então utilizado na posição de deflexão esquerda, mas desta vez com sinal invertido (negativo). Neste momento a corrente de soldagem sobe a um nível mais alto (nitidamente o arco aumenta ainda mais de "volume"). Rapidamente o arco é então defletido para a direita mantendo este nível de corrente de soldagem elevado (parada lateral direita). Por fim, observa-se que os níveis de tensão do eletroímã e corrente de soldagem, bem como os tempos de permanência nestes níveis, ficaram de acordo ao programado (Tabela 4).

\section{Efeito da Oscilação Magnética Sincronizada na Largura de Cordões}

Neste item são apresentados a sequência experimental, os parâmetros específicos utilizados, bem como os resultados e as respectivas análises da avaliação da oscilação magnética sincronizada com o processo TIG. São apresentadas grandezas elétricas resultantes (tanto do eletroímã, quanto do processo de soldagem), o aspecto superficial dos cordões obtidos e medidas relacionadas à largura dos cordões resultantes. Foi utilizada oscilação transversal/lateral à direção de soldagem. A tensão do eletroímã (amplitude de deflexão do arco) foi fixada em $30 \mathrm{~V}$, próximo ao limite do eletroímã para maximizar a deflexão do arco. Os tempos de parada (esquerda, central e direita) do arco foram configurados em diferentes valores entre si, conforme apresentado na Tabela 5, resultando em uma frequência de oscilação magnética de $1 \mathrm{~Hz}$. A corrente de soldagem para os ensaios de oscilação magnética sem sincronização (corrente constante) foi fixada em 150 A. Para avaliar o efeito da variação da corrente de soldagem em cada posição de parada do arco (oscilação magnética com sincronização), foram utilizados um nível de corrente esquerda, um de corrente central e um de corrente direita distintos entre si (Tabela 6), que, em combinação com os tempos de parada do arco em cada posição, resultaram em uma corrente média de $150 \mathrm{~A}$ (mesmo nível dos ensaios com oscilação magnética sem sincronização). Um ensaio com corrente constante em 150 A e sem oscilação do arco foi realizado para efeitos de comparação geral. A sequência de ensaios é resumida na Figura 10.

Tabela 5. Tempos de parada nas posições do arco com frequência de oscilação magnética resultante e correntes de soldagem nas respectivas posições de parada para a corrente média utilizada.

\begin{tabular}{cccc}
\hline $\begin{array}{c}\text { Tempo de Parada } \\
\text { Esquerda } \\
{[\mathrm{ms}]}\end{array}$ & $\begin{array}{c}\text { Tempo de Parada Central } \\
{[\mathrm{ms}]}\end{array}$ & $\begin{array}{c}\text { Tempo de Parada Direita } \\
{[\mathrm{ms}]}\end{array}$ & $\begin{array}{c}\text { Frequência de Oscilação } \\
{[\mathrm{Hz}]}\end{array}$ \\
\hline 300 & 250 & 200 & 1 \\
\hline $\begin{array}{c}\text { Corrente de Soldagem } \\
\text { Esquerda [A] }\end{array}$ & $\begin{array}{c}\text { Corrente de Soldagem } \\
\text { Central [A] }\end{array}$ & $\begin{array}{c}\text { Corrente de } \\
\text { Soldagem Direita [A] }\end{array}$ & $\begin{array}{c}\text { Corrente de Soldagem } \\
\text { Média [A] }\end{array}$ \\
\hline 210 & 111 & 158 & 150 \\
\hline
\end{tabular}

Tabela 6. Grandezas elétricas resultantes dos ensaios com processo TIG.

\begin{tabular}{|c|c|c|c|c|c|c|c|}
\hline \multirow[b]{2}{*}{ Ensaio } & \multicolumn{4}{|c|}{ Tensão do Eletroímã } & \multicolumn{3}{|c|}{ Tensão do Arco e Corrente de Soldagen } \\
\hline & $\begin{array}{l}\text { Tensão } \\
\text { Esquerda } \\
\text { Média [V] }\end{array}$ & $\begin{array}{l}\text { Tensão } \\
\text { Central } \\
\text { Média [V] }\end{array}$ & $\begin{array}{l}\text { Tensão } \\
\text { Direita } \\
\text { Média [V] }\end{array}$ & $\begin{array}{c}\text { Frequência } \\
\text { Resultante } \\
{[\mathrm{Hz}]}\end{array}$ & $\begin{array}{l}\text { Tensão } \\
\text { Média [V] }\end{array}$ & $\begin{array}{c}\text { Corrente } \\
\text { Média [A] }\end{array}$ & $\begin{array}{c}\text { Frequência } \\
\text { Resultante } \\
{[\mathrm{Hz}]}\end{array}$ \\
\hline \multicolumn{8}{|c|}{ Configuração sem oscilação magnética } \\
\hline 1 & - & 0,07 & - & - & 12,86 & 154,5 & - \\
\hline \multicolumn{8}{|c|}{ Configuração com oscilação magnética sem sincronização } \\
\hline 2 & $-27,51$ & $-0,24$ & 27,72 & 1,00 & 12,86 & 154,4 & - \\
\hline \multicolumn{8}{|c|}{ Configuração com oscilação magnética com sincronização } \\
\hline 3 & $-27,50$ & 0,25 & 27,69 & 0,99 & 13,33 & 153,9 & 1,01 \\
\hline
\end{tabular}




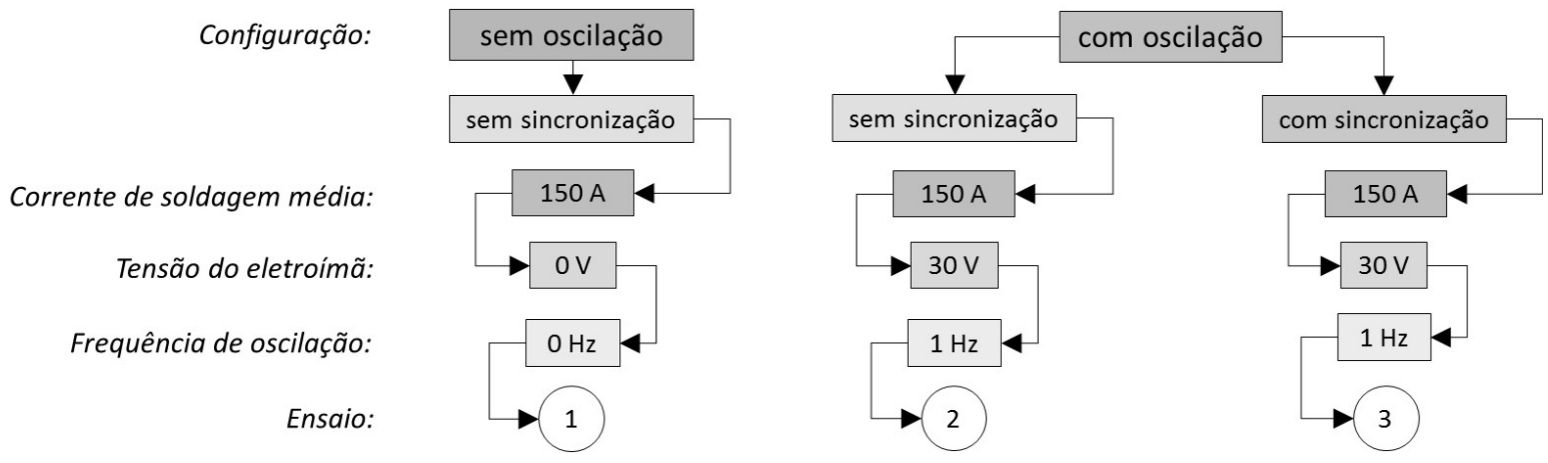

Figura 10. Fluxograma dos ensaios realizados com o processo TIG.

\subsection{Grandezas elétricas resultantes}

A Tabela 6 apresenta as grandezas elétricas resultantes dos ensaios com processo TIG compiladas a partir da aquisição dos sinais elétricos envolvidos. Em linhas gerais, as grandezas elétricas, inclusive aquelas resultantes do ensaio com oscilação magnética com sincronização, ficaram de acordo com o programado, evidenciando o bom funcionamento do sistema de controle do eletroímã e da fonte de soldagem. Os campos magnéticos aplicados ao arco nas laterais foram os mesmos, como indicado pelos valores virtualmente iguais de tensão do eletroímã à esquerda e à direita. Cabe ressaltar, entretanto, que na configuração com oscilação magnética com sincronização as deflexões à esquerda e à direita foram diferentes, pois as correntes de soldagem nas respectivas posições foram diferentes (a deflexão depende do campo magnético, mas também da corrente como demonstrado na Equação 14).

\subsection{Aspecto superficial dos cordões obtidos}

A Figura 11 apresenta o aspecto superficial dos cordões de solda resultantes da soldagem TIG com oscilação magnética com e sem sincronização e ainda da soldagem sem oscilação do arco. Nota-se o esperado aumento da largura dos cordões com a utilização da oscilação magnética, contudo mais pronunciadamente para o caso com sincronização. Com a utilização da oscilação magnética sincronizada, nota-se ainda o que se pode chamar de marcas de fusão (marcas de atuação das diferentes capacidades de fusão do arco em cada posição de parada) bem definidas. As marcas denotam algo como marcas de pulsação de corrente típicas do processo TIG Pulsado, só que deslocadas tanto longitudinalmente (como seria no TIG Pulsado) quanto transversalmente em relação à linha central do cordão. Essas marcas de fusão serão mais evidentes (espaçadas) para maiores tensões de eletroímã (amplitudes de deflexão de arco) e velocidades de soldagem. Essa capacidade diferenciada de produzir marcas de

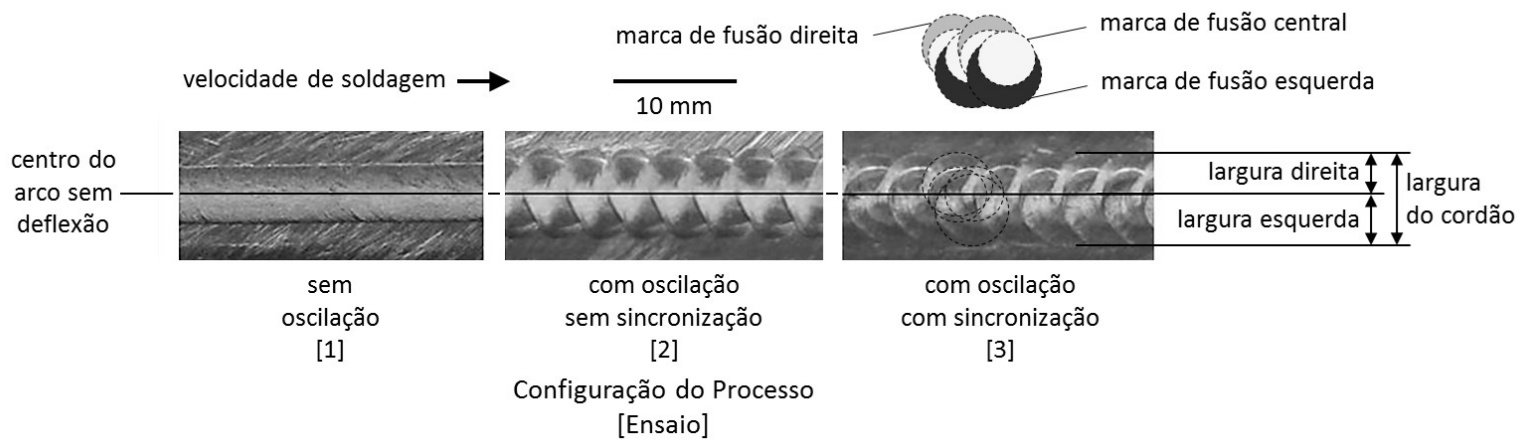

Figura 11. Aspecto superficial dos cordões de solda obtidos com o processo TIG com linhas centrais correspondendo ao centro do arco sem deflexão (trajetória da extensão da ponta do eletrodo obtida por meio de marcações previamente realizadas nos corpos de prova) / Obs.: largura total = largura direita medida + largura esquerda medida (as larguras direita e esquerda foram baseadas em médias de medições efetuadas em regiões de início, meio e fim de cada cordão). 
fusão poderia contribuir para cordões de boa qualidade, por exemplo, evitando segregação de fases e quebrando/ refinando os grãos formados durante a solidificação. Nota-se, ainda nos cordões com oscilação, "vales" às margens esquerda e direita, nitidamente mais curtos e suaves na margem esquerda do cordão produzido com a configuração com oscilação com sincronização, o que evidencia a atuação diferenciada dos níveis de corrente distintos utilizados.

\subsection{Medidas relacionadas à largura dos cordões}

Os cordões resultantes da soldagem TIG foram fotografados com escala e as medições dos parâmetros de largura desses cordões foram executadas também com auxílio do software ImageJ. A Figura 12 (à esquerda) mostra o comportamento da largura dos cordões para diferentes configurações do processo TIG, com corrente média de soldagem de $150 \mathrm{~A}$. Como esperado, o menor valor de largura total foi para o caso de corrente constante sem oscilação. A configuração com oscilação com sincronização resultou em maior largura total quando comparada à configuração de corrente constante com oscilação (sem sincronização). A Figura 12 (à esquerda) mostra também as larguras parciais (esquerda e direita) para melhor análise do efeito da sincronização dos níveis de corrente de soldagem com a posição do arco durante a oscilação magnética. Nota-se que as configurações sem oscilação e com oscilação sem sincronização levaram à formação de cordões balanceados, ou seja, com larguras esquerdas similares às larguras direitas, algo esperado principalmente para o caso sem oscilação. Ao que parece, no caso com oscilação sem sincronização, o pequeno acréscimo de tempo na parada lateral esquerda (100 ms) em relação à parada lateral direita não foi suficiente para desbalancear a contribuição das larguras parciais na formação da largura total do cordão. Já a configuração com oscilação com sincronização levou à formação de larguras parciais significativamente desbalanceadas; aumentou a largura esquerda e diminuiu a largura direita do cordão, com efeito mais pronunciado na largura esquerda (ver também o cordão do ensaio 3 na Figura 11). Comparando o efeito nas larguras total, esquerda e direita, para os parâmetros utilizados, fica evidente que a largura total do cordão na configuração com oscilação com sincronização foi definida sobretudo pela largura esquerda. Isso indica que o sistema de oscilação magnética sincronizada foi capaz de controlar a formação do cordão (pelo menos em termos de largura na superfície da chapa) como desejado, já que a maior corrente e tempo de parada foram selecionados para a posição do arco à esquerda.

A Figura 12 (à direita) mostra os valores de energia (térmica) de soldagem obtidos em cada posição de parada do arco para os testes com oscilação (calculados pelo produto entre corrente de soldagem, tensão de arco e tempo de parada em cada posição do arco) e sem oscilação magnética (calculado pelo produto entre corrente de soldagem, tensão de arco e tempo médio equivalente das paradas em cada posição do arco nos casos com oscilação). Nota-se que com a sincronização da corrente com a posição de atuação do arco foi possível atingir um
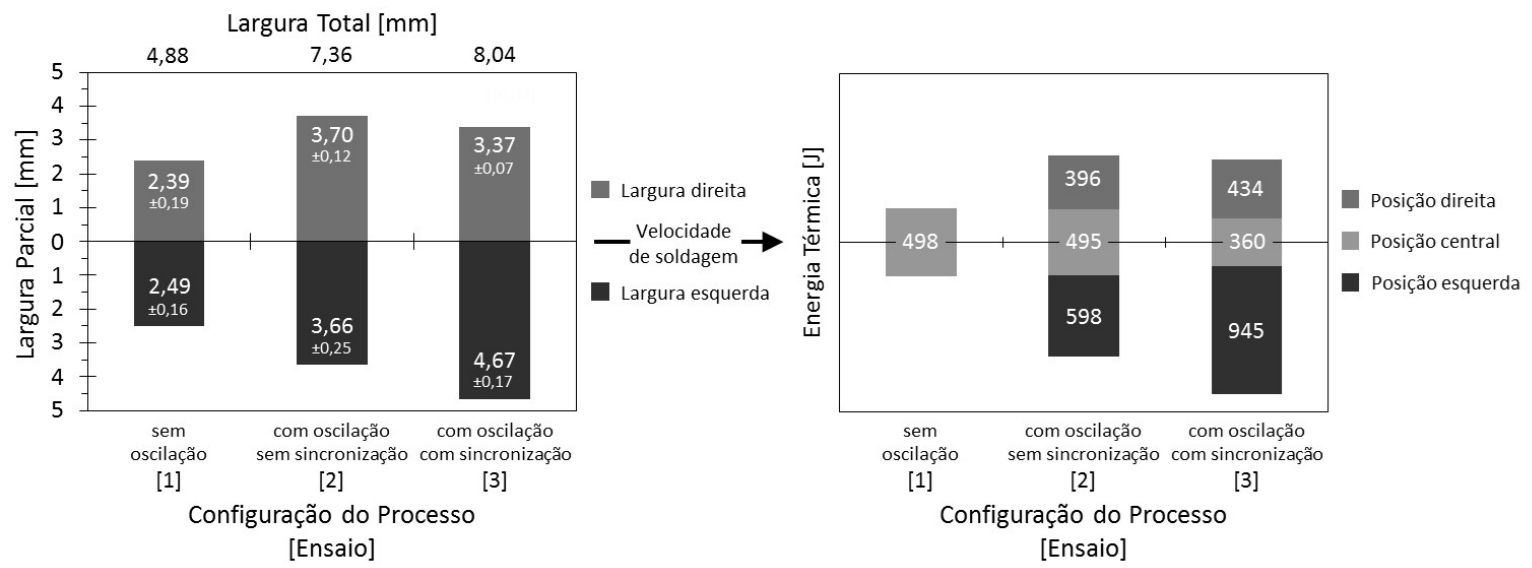

Figura 12. (à esquerda) Largura do cordão de solda para diferentes configurações do processo TIG com corrente média de soldagem de $150 \mathrm{~A}$ (os valores de desvio padrão das larguras parciais aparecem precedidos do sinal \pm ); (à direita) Capacidade de fusão do arco representada pela energia (térmica) de soldagem em cada posição de parada do arco (energia térmica $=$ tensão do arco $\times$ corrente de soldagem $\times$ tempo de parada) para diferentes configurações do processo TIG com corrente média de soldagem de $150 \mathrm{~A}$. 
nível de energia bem mais alto (945 J) do lado esquerdo do cordão sem, no entanto, mudar a corrente média utilizada (ver Tabela 6). Essa energia significativamente maior direcionada ao lado esquerdo justifica a largura parcial bem maior à esquerda e sua contribuição para uma maior largura total (maior espalhamento do cordão). Vale ressaltar que a maior contribuição para a aumento significativo da energia do arco (capacidade de fusão) no lado esquerdo foi oriunda da corrente de soldagem selecionada (ver Tabela 5), já que o tempo de parada do arco (apesar de maior) à esquerda não foi muito diferente dos tempos selecionados para outras posições do arco (ver Tabela 5) e a tensão de arco resultante em cada posição pouco variou mesmo com a deflexão magnética (ver tensões de arco médias similares na Tabela 6). O fato da largura direita ter diminuído um pouco, com a adição da sincronização à oscilação, pode estar relacionado à contribuição vinda da energia da posição central. Apesar da energia ligeiramente maior à direita na configuração com sincronização (434 J) em relação à sem sincronização (396 J), a energia na posição central foi razoavelmente menor (360 J versus $495 \mathrm{~J}$, respectivamente). Com relação ao efeito geral da energia térmica da posição central, em termos de largura, pode-se dizer que ela influencia indiretamente nas larguras parciais e tem como função "ligar" as duas fusões laterais (ver marcas de fusão na Figura 11).

O controle da poça de fusão demonstrado pelo uso da sincronização dos níveis de corrente na soldagem TIG com a oscilação magnética poderia ser explorado, por exemplo, na soldagem de materiais dissimilares, em juntas com materiais de diferentes espessuras, em passes de raiz, em chanfros estreitos, etc., sempre procurando direcionar mais ou menos calor/fusão de acordo com a posição do arco. Um melhor controle da geometria do cordão poderia ser efetuado pela otimização do direcionamento da energia do arco de maneira mais flexível (variações na corrente de soldagem e nos tempos e posições de parada do arco). Antes, porém, faz-se necessário avaliar a técnica desenvolvida com maiores níveis de deflexão magnética (inclusive com possibilidade de aplicação de campos magnéticos distintos em cada lateral), com menores e maiores níveis de corrente de soldagem, maiores frequências de oscilação e mesmo em aplicações exploratórias na soldagem TIG com adição de arame e na soldagem MIG/MAG, levando em conta efeitos, além de na largura, também no perfil de penetração dos cordões.

\section{Conclusões}

- A partir da avaliação do sincronismo dos sinais de controle do eletroímã e dos sinais provenientes da fonte de soldagem (tensão do arco e corrente de soldagem) foi evidenciada a eficiência do sistema de sincronização desenvolvido.

- O modelo teórico proposto para a deflexão magnética do arco indicou o mesmo comportamento verificado nos experimentos realizados, mostrando que a deflexão é diretamente proporcional ao campo magnético, ao quadrado do comprimento do arco e inversamente proporcional à corrente de soldagem, inclusive em concordância com outros modelos encontrados na literatura.

- Apesar de representar a tendência de comportamento real do fenômeno de deflexão do arco, o modelo teórico de deflexão não conseguiu estimar com razoabilidade o valor da deflexão real.

- A configuração de soldagem TIG com oscilação magnética sincronizada resultou em maior valor de largura de cordão quando comparada à configuração de corrente constante com oscilação (oscilação convencional).

- Na soldagem TIG com sincronização, a largura do lado esquerdo do cordão, para onde foi direcionado maior nível de energia de soldagem (principalmente pelo nível de corrente utilizado), influenciou mais o aumento da largura total, demonstrando que o sistema de oscilação magnética sincronizada foi capaz de controlar a formação do cordão (pelo menos em termos de largura na superfície da chapa) como desejado. Ou seja, a distribuição otimizada da energia de soldagem possibilitou aumentar a largura parcial esquerda e, assim, a largura total do cordão de solda sem, no entanto, aumentar a corrente média utilizada.

\section{Agradecimentos}

Os autores agradecem ao CNPq (projeto 458428/2014-0), FAPEMIG (projeto APQ-00858-14) e CAPES pelo suporte financeiro e bolsas de estudo e ao Centro para Pesquisa e Desenvolvomento de Processos de Soldagem (Laprosolda-UFU) pela infraestrutura utilizada. 


\section{Referências}

[1] Mello A. Houston, we have a welder shortage. Chronicle. 2013 Set. 27. [acesso em 16 fev. 2016]. Disponível em: http:// www.chron.com/jobs/article/Houston-we-have-a-weldershortage-4851720.php

[2] Smith C. How the welder shortage affects the infrastructure. The Fabricator. 2013 Nov. 19. [acesso em 16 fev. 2016]. Disponível em: http://www.thefabricator.com/article/testingmeasuring/ how-the-welder-shortage-affects-the-infrastructure

[3] Greene WJ. Magnetic oscilation of wedling arc. United States patent US 2,920,183. 1960.

[4] Blunt FJ, Ribton C. N. Design of electromagnets for arc oscillation in surfacing applications, for MIG and TIG processes. Cambridge: TWI; 2000. (TWI Industrial Member Report Summary, 541/1996).

[5] Ueyama T, Ohnawa T, Tanaka M, Nakata K. Occurrence of arc interference and interruption in tandem pulsed gma weldingstudy of arc stability in tandem pulsed gma welding (Report 1). Quarterly Journal of the Japan Welding Society. 2005;23(4):515525. http://dx.doi.org/10.2207/qjjws.23.515.

[6] Reis RP, Scotti A, Norrish J, Cuiuri D. Investigation on welding arc interruptions in the presence of magnetic fields: welding current influence. IEEE Transactions on Plasma Science. 2012;40(3):870876. http://dx.doi.org/10.1109/TPS.2012.2182781.

[7] Reis RP, Scotti A, Norrish J, Cuiuri D. Investigation on welding arc interruptions in the presence of magnetic fields: arc length, torch angle and current pulsing frequency influence. IEEE Transactions on Plasma Science. 2013;41(1):133-139. http:// dx.doi.org/10.1109/TPS.2012.2230650.

[8] Reis RP, Souza D, Ferreira D Fo. Arc interruptions in tandem pulsed gas metal arc welding. Journal of Manufacturing Science and Engineering. 2015;137(1):011004, 011004-011009. http:// dx.doi.org/10.1115/1.4028681.

[9] Kumar A, Shailesh P, Sundarrajan S. Optimization of magnetic arc oscillation process parameters on mechanical properties of AA 5456 Aluminum alloy weldments. Materials \& Design. 2008;29(10):1904-1913. http://dx.doi.org/10.1016/j. matdes.2008.04.044.
[10] Lim YC, Yu X, Cho JH, Sosa J, Farson DF, Babu SS, et al. Effect of magnetic stirring on grain structure refinement. Part 1: autogenous nickel alloy welds. Science And Technology Of Welding And Joining. 2010a;15(7):583-589. http://dx.doi.org/ 10.1179/136217110X12720264008277.

[11] Lim YC, YuX, Cho JH, Sosa J, Farson DF, Babu SS, et al. Effect of magnetic stirring on grain structure refinement. Part 2: nickel alloy weld overlays. Science And Technology Of Welding And Joining. 2010b;15(5):400-406. http://dx.doi.org/10.1179/136 $217110 \times 12720264008231$.

[12] Sundaresan S, Ram GDJ. Use of magnetic arc oscillation for grain refinement of gas tungsten arc welds in $\alpha-\beta$ titanium alloys. Science And Technology Of Welding And Joining. 1999;4(3):151160. http://dx.doi.org/10.1179/136217199101537699.

[13] Chen XQ, Smith JS, Lucas J. Microcomputer controlled arc oscillator for automated TIG welding. Journal Of Microcomputer Applications. 1990;13(4):347-360. http://dx.doi.org/10.1016/0745 7138(90)90034-5.

[14] Kang YH, Na SJ. Characteristics of welding and arc signal in narrow groove gas metal arc welding using electromagnetic arc oscillation: experiments produce optimum parameters for obtaining uniform and sufficient groove face penetration. Welding Journal. 2003;82(5):93s-99s.

[15] Dutra JC, Bidese E, Bonacorso NG, Silva RHG. Improving surfacing performance with GMAW: a method of synchronizing polarity is used for applications that require minimal dilution. Welding Journal. 2013;92(5):42-47.

[16] Lancaster JF. The physics of welding. 2. ed. Oxford: Pergamon Press; 1986.340 p.

[17] Kang YH, Na SJ. A study on the modeling of magnetic arc deflection and dynamic analysis. Welding Journal. 2002;81(1):8s-13s.

[18] Ueyama T, Ohnawa T, Tanaka M, Nakata K. Occurrence of arc interaction in tandem pulsed gas metal arc welding. Science and Technology of Welding and Joining. 2007;12(6):523-529. http://dx.doi.org/10.1179/174329307X173715. 